\title{
Condicionants socioeconòmics del rendiment acadèmic
}

\author{
Anna Ronquillo \\ Carme Saurina \\ Joan Solé \\ Universitat de Girona
}

\section{Resum}

En aquest treball es presenten els principals resultats d'una investigació sobre la relació entre les característiques socioeconòmiques $\mathrm{i}$ el rendiment acadèmic dels estudiants a nivell universitari. La mostra està formada per estudiants de les diplomatures en Ciències Empresarials de Girona i Sabadell. Els resultats mostren que els estudiants es poden classificar en tres categories socials: baixa, mitjana i alta. També mostren que el rendiment acadèmic no es pot associar a una categoria determinada. Això és explicable pel fet que el sistema educatiu ja ha realitzat la selecció en els nivells previs als estudis superiors.

Paraules clau: educació, formació, rendiment acadèmic.

Abstract. The social economic circumstances and the academic rentability.

In this paper we present the results of a research about the relationship betwen the social economic characteristics of the students and their academiec achievement at university level. The sample was formed with students of business administration from the business schools of Girona and Sabadell. The results show that the students can be classified in three social economic categories: low middle and high. They also show that the academic achieveent can not be associated to any dermined category. This can be explained by the fact that the educational system has alread done a selection in previous levels of studies.

Key words: education, training, academic rentability.

\begin{aligned} & \multicolumn{2}{c}{ Sumari } \\ & Introducció 4. Conclusions \\ & 1. Marc teòric Annex \\ & 2. Metodologia Bibliografia \\ & 3. Resultats \end{aligned}

\section{Introducció}

La importància que va adquirint l'educació en les societats desenvolupades és cada cop més gran, tant per als nivells bàsics com per als superiors. En aquests últims, l'augment de la població universitària és un fet incontestable que planteja interrogants fins $i$ tot al mateix paper $i$ a la mateixa finalitat que se supo- 
sa que ha de tenir i que ha de dur a terme la universitat. D'altra banda, des d'una perspectiva més propera a les ciències socials en general i a la ciència econòmica en particular, aquestes tendències condueixen al plantejament de qüestions, que si bé no són noves en els seus àmbits d'estudi, sí que adquireixen una rellevància especial en aquest context.

L'educació superior, entesa com un més dels serveis proveïts amb béns públics, planteja, en la mesura que va creixent en importància, temes no exempts d'interès, com són els relacionats amb l'eficàcia en el desenvolupament de la seva missió. Això té a veure amb la correcta utilització dels recursos públics destinats a aquesta finalitat $\mathrm{i}$ amb el profit que puguin obtenir els estudiants durant el seu pas per les aules universitàries.

En aquest treball es realitza una observació empírica de variables considerades influents en el rendiment acadèmic dels estudiants universitaris, concretament en aquells que estan matriculats a les diplomatures de Ciències Empresarials de Girona i Sabadell durant el curs 93-941. Entre els factors que tradicionalment s'han relacionat amb el rendiment dels estudiants es poden destacar:

- Les característiques personals o psicològiques.

- L'entorn social i familiar.

- L'oferta de places (condicionant de l'accés a les diferents carreres).

- El medi universitari o centre.

- Les expectatives del mercat de treball.

\section{Marc teòric}

La literatura sobre els factors que expliquen per què i com els diferents grups socials es relacionen amb el sistema educatiu i amb la cultura en general, dóna pistes de molts dels condicionants del rendiment acadèmic. La qüestió ha estat analitzada des de diverses disciplines com són la sociologia, la psicologia i, més recentment, l'economia. Entre els diferents estudis podem distingir dues perspectives:

- Una primera que parteix de la hipòtesi que els estudiants porten en la seva manera de ser una predisposició favorable o desfavorable cap a un rendiment acadèmic òptim. Aquesta actitud es relaciona amb l'origen social de la persona.

- Una segona per a la qual el rendiment dels estudiants universitaris no prové solament del seu origen social, sinó també de la situació que la mateixa universitat i la societat en general creen o constitueixen. A aquesta situació podem anomenar-la «medi» o «ambient» universitari. En altres termes, en

1. Entenem per rendiment acadèmic: «L'adquisició en el temps previst, d'acord amb els programes $\mathrm{i}$ amb els nivells acadèmics, dels coneixements i les habilitats que la institució de què es tracta hagui marcat. Aquesta situació és sancionada amb la suficiència credencial». La definició es pren en base a l'adoptada als informes preparatoris del treball Estudi sobre el fracàs escolar a Catalunya, realitzat pel Centre d'Iniciatives per a la Recerca a l'Europa Mediterrània (CIREM, 1992). 
aquest treball entenem per mitjà, l'ambient o la situació de la universitat, l'estat en què es troba la institució universitària a nivell general i que en bona part té el seu origen en l'existència d'una oferta de places en quantitat i qualitat donades en cada moment.

Mencionem aquí algunes de les aportacions de les dues perspectives que hi ha en la base d'aquesta investigació. En la primera, podem trobar treballs ja clàssics en la literatura com són els de Bernstein (1965), Bourdieu i Passeron (1967), Boudon (1973), Schutz (1961), Becker (1975), Blaug (1970), Ginés Mora i Cea (1992). Per a Bernstein, Bourdieu i Passeron, l'origen social exerceix influència sobre l'individu en la mesura que la família es la instància de socialització d'aquest. En la institució familiar, s'aprèn el tipus de llenguatge utilitzat per la classe social a la qual aquesta pertany, a més dels rols individuals, patrons de comportament i actituds cap als diferents àmbits de la vida social, entre els quals es troben els referits a l'ensenyament. L'exposat es concreta en el fet que mentre a les classes mitjanes i altes tendeixen a ser apreciades en els individus característiques tals com la racionalització, el voluntarisme o l'autoavaluació, això no succeeix igual en les classes humils, atrapades més sovint en el fatalisme, la passivitat i el conformisme.

Boudon enfoca el tema a partir de l'anàlisi sobre cost i benefici. Seguir estudiant comporta uns beneficis que un observador de la societat pot constatar, com també uns costos associats. L'origen social exerceix influència sobre l'individu a l'hora de realitzar valoracions d'aquests costos i beneficis. Aquesta influència es concreta en què un alumne de classe baixa observi probablement que pel fet de seguir estudiant pugui obtenir uns beneficis per a ell grans en termes d'ascens social. Aquests beneficis possiblement siguin més grans que els que esperi obtenir una persona d'idèntiques característiques de classe alta per una simple qüestió de posició de partida relativa diferent en l'escala social.

Per a Schutz, Becker i Blaug, en general, les decisions que pren tot individu per cursar estudis superiors provenen dels rendiments que aquest preveu que pot obtenir pel fet de dedicar una part més gran del seu temps disponible a l'estudi. Per a aquests autors, els guanys derivats de perllongar els anys d'estudi es mesuren principalment en termes de retribucions més grans que haurà de percebre l'individu cultivat en la seva futura vida laboral. Finalment, Mora i Cea, a partir del disseny d'un model teòric, analitzen aquells trets que caracteritzen la demanda d'estudis superiors, i arriben a la conclusió que el rendiment acadèmic previ i la localització del centre universitari en el territori són factors explicatius d'aquesta demanda. Quant als estudis que incorporen en la seva anàlisi la situació dels centres o les característiques del medi universitari, a més de les peculiaritats dels individus, són destacables treballs com els de Moltó i Oroval (1984), Apodaka i Grao (1991) o Latiesa (1992).

Com ja hem apuntat, societat $i$ universitat creen o constitueixen una «situació» o un medi on es desenvolupa la tasca d'aquesta última. Aquest medi repercuteix sobre aspectes relacionats amb la vida estudiantil i en particular sobre el rendiment acadèmic dels alumnes. Moltó i Oroval assenyalen el poder dis- 
criminatori que pels grups socials més desfavorits pot implicar una política de despesa pública en ensenyament superior que no tingui en compte les característiques dels usuaris d'aquest servei quan és proveït públicament. Si no existeix un sistema de beques eficaç, encara que els matriculats paguin preus "públics" per l'ensenyament superior, han de fer front a costos privats considerables pel simple fet de ser a la universitat. Si fer front a aquests costos comporta dedicar una part del temps disponible a una activitat laboral remunerada, això pot tenir conseqüències sobre el rendiment acadèmic.

Per la seva part, Latiesa també es refereix a aspectes com la receptivitat, la motivació i el nivell d'exigència del professorat o la dotació d'instal.lacions suposadament òptimes del centre (biblioteques, sales d'estudi, etc.), a més de l'importantíssim aspecte de la limitació quantitativa de l'oferta de places universitàries. El desajustament entre oferta i demanda pot traduir-se, en el cas en què aquesta última sigui més gran que la primera, en processos de selecció dels demandants que els portin a estudiar carreres que no figuraven en la seva primera elecció d'estudis superiors. Aquest fet repercuteix, primerament, sobre la motivació dels estudiants i, després, sobre el seu rendiment acadèmic.

Quant a l'ambient «intern» del centre, una biblioteca dotada convenientment $\mathrm{o}$, en general, unes instal.lacions òptimes, $\mathrm{i}$ un professorat motivat en la seva tasca de transmissió de coneixements, contribueixen també positivament a un bon aprofitament per part dels alumnes. Finalment, Apodaka i Grao destaquen que la demanda d'estudis superiors i el rendiment acadèmic es veuen influenciats respectivament per la distribució geogràfica dels centres universitaris, com també pel rendiment acadèmic en els nivells d'ensenyament mitjà.

\section{Metodologia}

Per a aquest estudi s'han analitzat les dades provinents d'una enquesta realitzada als estudiants de tercer curs de l'Escola Universitària d'Estudis Empresarials de la Universitat Autònoma de Barcelona (UAB) i de la Facultat de Ciències Jurídico-Econòmiques, estudis de Ciències Econòmiques i Empresarials, de la Universitat de Girona (UdG), curs 93-94. En el quadre 1 tenim el nombre d'estudiants que han contestat el qüestionari (els assistents a classe de l'assignatura troncal comuna de Macroeconomia dels grups de matí i tarda en els dos centres analirzats) i el nombre total de matriculats en aquesta assignatura. Les variables utilitzades en l'estudi es poden dividir en els tipus assenyalats en el quadre 2 . Les anàlisis estadístiques efectuades han estat de tipus univariant, bivariant ( $\chi 2$ amb variables qualitatives, $t$-Student amb les variables quantitatives) i multivariant (anàlisi de correspondències múltiples i de tipologies).

Respecte a l'anàlisi multivariada i a causa de l'existència majoritària de variables qualitatives, s'efectua una anàlisi de correspondències múltiples que permet visualitzar i relacionar les modalitats de les variables categòriques de motivació i d'expectatives, com també les variables acadèmiques, en funció de les variables socioeconòmiques, geogràfiques i de situació personal de l'estudiant que s'han escollit com a variables actives definitòries de l'exploració. 
Quadre 1

\begin{tabular}{lcc}
\hline Centre & $\begin{array}{l}\text { Població } \\
\text { matriculada }\end{array}$ & $\begin{array}{l}\text { Nombre } \\
\text { d'enquestats }\end{array}$ \\
\hline Diplomatura en Ciències Empresarials (Girona) & 505 & 211 \\
Diplomatura en Ciències Empresarials (Sabadell) & 321 & 194 \\
\hline Total & $\mathbf{8 2 6}$ & $\mathbf{4 0 5}$ \\
\hline
\end{tabular}

Quadre 2

\begin{tabular}{|c|c|}
\hline Tipus de variable & Variable \\
\hline Variables de perfil de l'enquestat & $\begin{array}{l}\text { Edat, sexe, estudis previs, procedència geogràfi- } \\
\text { ca de l'estudiant, categoria socioprofessional }\end{array}$ \\
\hline Variables d'entorn familiar i social & $\begin{array}{l}\text { Procedència geogràfica, estudis, categoria socio- } \\
\text { professional i llengua del pare i de la mare de l'es- } \\
\text { tudiant, situació laboral }\end{array}$ \\
\hline Variables acadèmiques & $\begin{array}{l}\text { Any d'inici dels estudis, torn de classes al qual } \\
\text { s'assisteix, centre on s'estudia, tipus de matrícu- } \\
\text { la, nombre d'assignatures suspeses d'altres cursos }\end{array}$ \\
\hline \multirow[t]{6}{*}{$\begin{array}{l}\text { Variables motivacionals } \\
\text { i de percepció de l'entorn }\end{array}$} & $\begin{array}{l}\text { Elecció de la mateixa universitat o d'una altra } \\
\text { de diferent si no s'hi haguessin ofert els estudis } \\
\text { elegits }\end{array}$ \\
\hline & Opció carrera \\
\hline & $\begin{array}{l}\text { Valoració de les possibilitats d'ocupació, presti- } \\
\text { gi i ingressos des del punt vista personal }\end{array}$ \\
\hline & $\begin{array}{l}\text { Valoració de les possibilitats d'ocupació, presti- } \\
\text { gi i ingressos des del punt vista social }\end{array}$ \\
\hline & $\begin{array}{l}\text { Motivació per l'estudi: satisfacció pels estudis que } \\
\text { es realitzen, explicacions dels pares, dedicar-se a } \\
\text { una activitat relacionada amb el que s'estudia, } \\
\text { augmentar les possibilitats de trobar feina }\end{array}$ \\
\hline & $\begin{array}{l}\text { Motiu d'inici dels estudis: raons familiars, asses- } \\
\text { sorament extern a la família, capacitat adequada, } \\
\text { promoció professional, vocació científica, conti- } \\
\text { nuació de la formació, no dificultat dels estudis. }\end{array}$ \\
\hline \multirow[t]{2}{*}{ Variables d'expectatives } & Aspiracions de graduació acadèmica \\
\hline & $\begin{array}{l}\text { Expectatives dels estudis: adquisició d'un nivell } \\
\text { cultural elevat, obtenir un títol, adquisició de } \\
\text { qualificació professional, formació científica i } \\
\text { investigadora }\end{array}$ \\
\hline \multirow[t]{3}{*}{ Variables de costos } & Classes particulars \\
\hline & Transports \\
\hline & Llibres, fotocòpies i publicacions \\
\hline
\end{tabular}


Concretament, les variables actives escollides han estat les de perfil de l'enquestat $i$ les d'entorn familiar i social.

Caracteritzats doncs els eixos factorials segons la perspectiva adoptada per les variables socioeconòmiques i de perfil de l'estudiant, s'interpreten, per projecció sobre els mateixos eixos, les variables il.lustratives representades per les diferents modalitats de les variables acadèmiques, les motivacionals i les variables que expressen les expectatives dels estudiants enquestats. Finalment, i sobre els eixos factorials obtinguts, es realitza una classificació dels estudiants i s'analitzen les tipologies presentades pels diferents grups o clústers.

\section{Resultats}

\subsection{Anàlisi univariant $i$ bivariant}

I. Perfil i entorn social dels estudiants

Quadre 3.

\begin{tabular}{|c|c|c|c|}
\hline Variable de perfil & Girona & Sabadell & \\
\hline Edat (mitjana) & 22,16 & 22,78 & \\
\hline Sexe & $\mathrm{H}: 36,02 \%$ & D: $63,98 \%$ & D: $57,51 \%$ \\
\hline
\end{tabular}

$\mathrm{H}$ : homes, D: dones.

Hi ha una diferència significativa (nivell de confiança del 95\%) entre l'edat dels estudiants de Girona i de Sabadell de mig any aproximadament. La procedència geogràfica dels pares no és significativament diferent de la de les mares dels estudiants, però sí que ho és entre els pares de Girona i Sabadell. En el primer cas, el $73 \%$ prové de les comarques de Catalunya, mentre que en el segon solament ho fa el $48 \%$. Els estudiants, en canvi, en la seva immensa majoria són nascuts a Catalunya. A Girona, el $75,5 \%$ dels alumnes parlen en català amb els seus pares. A Sabadell aquest percentatge és del $45 \%$.

Els estudis dels pares i de les mares dels alumnes són principalment primaris $(58,7 \%$ per als pares, $68,9 \%$ per a les mares). La categoria socioprofessional paterna dels enquestats és majoritàriament $(54,07 \%)$ la de treballador no especialitzat dels diferents sectors econòmics (44,7\% a Girona i 49,2\% a Sabadell). Per la seva part, les mares (més de la meitat) són mestresses de casa. En cas de treballar, la seva categoria socioprofessional coincideix bàsicament amb la dels pares.

\section{Situació acadèmica dels estudiants}

Els estudis previs dels estudiants de les institucions analitzades es corresponen amb els legalment establerts (un 30\% de FP, i la resta procedents de COU). Respecte a l'horari d'assistència a classe a Girona, un 71,58\% dels alumnes assisteix als cursos del matí $i$ un $28,44 \%$ als de tarda o nit. A Sabadell un $50,26 \%$ pertany als grups de matí i el $49,22 \%$ restant als grups de tarda o nit. 


\section{Rendiment acadèmic}

El rendiment acadèmic s'ha mesurat mitjançant les variables que fan referència a l'any d'inici dels estudis (la qual cosa ens dóna una idea del possible retard en l'evolució normal dels estudis), i amb el nombre d'assignatures pendents de cursos anteriors. Respecte a l'any acadèmic d'inici dels estudis, a Girona el $63 \%$ dels enquestats declara que els ha començat el curs 91-92, mentre que a Sabadell solament el 38,14\%. (L'any correcte, en cas d'un seguiment normal del pla d'estudis, seria el 91-92). Hi ha una diferència significativa (nivell de confiança del 95\%) d'un any aproximadament entre l'any d'inici dels estudis entre Girona i Sabadell. De mitjana, els estudiants de Girona han començat els estudis un any després que els de Sabadell.

A Sabadell, hi ha una relació significativa (nivell de confiança del 95\%) entre l'any d'inici dels estudis i estudis previs. L'any d'inici dels estudis és anterior en el cas dels alumnes procedents de la formació professional. A Girona, hi ha una relació significativa (nivell de confiança del $95 \%$ ) entre l'any d'inici dels estudis i el sexe. Les dones $(69,6 \%)$, en més gran mesura que els homes $(52,6 \%)$, han començat els cursos en el moment que correspon segons el seu pla d'estudis. A Girona el $64,93 \%$ dels estudiants declara no tenir cap assignatura pendent de cursos anteriors. A Sabadell, el 25,56\%. Els que diuen que en tenen una o dues són el $26,54 \%$ a Girona i el $42,78 \%$ a Sabadell. Hi ha una diferència significativa (nivell de confiança del 95\%) d'1,13 assignatures pendents entre Girona i Sabadell. A Girona el nombre d'assignatures pendents és menor que a Sabadell.

\section{Motivacions $i$ actituds}

Entre els motius que han influït per prendre la decisió de començar a estudiar Empresarials destaquen, per aquest ordre:

- Veure's capacitat per a la realització d'aquests estudis.

- El consell d'altres persones (professors, psicòlegs, gent que havia fet la diplomatura).

- Pensar que es tractava d'una carrera facil.

A Girona hi ha una relació (nivell de confiança del 95\%) entre trobar la diplomatura d'Empresarials facil i el nivell d'estudis dels pares. Els fills de pares amb estudis superiors o secundaris troben la diplomatura més facil que la resta dels estudiants.

Els estudis d'Empresarials són valorats positivament respecte $\mathrm{a}^{2}$ :

2. La distinció entre valoracions personals i socials té el seu origen en la voluntat de diferenciació entre el que una persona valora per ella mateixa (valoracio personal), del que pensi que les altres opinen sobre el que ell o ella està valorant o reflexionant. Dos exemples poden ser útils per acabar de perfilar el que es pretén explicar: "Crec que els estudis d'Empresarials tenen unes bones possibilitats d'ocupación (valoració personal); "Crec que en general la societat pensa que els estudis d'Empresarials tenen unes bones possibilitats d'ocupacióm (valoració social). 
Quadre 4.

\begin{tabular}{lcc}
\hline & \multicolumn{2}{c}{$\%$ De valoració positiva } \\
Valoracions personals & Girona & Sabadell \\
\hline Possibilitats d'ocupació & 46 & 57,3 \\
Possibilitats de prestigi & 12,3 & 23,3 \\
Possibilitats d'ingressos & 12,3 & 19,3 \\
\hline
\end{tabular}

Quadre 5.

\begin{tabular}{lcc}
\hline Valoracions personals & \multicolumn{2}{c}{ \% De valoració positiva } \\
\hline Possibilitats d'ocupació & 54,5 & Sabadell \\
\hline Possibilitats de prestigi & 28,1 & 66,7 \\
Possibilitats d'ingressos & 37,6 & 45,4 \\
\hline
\end{tabular}

Més de la meitat dels enquestats $(56,8 \%)$ diu que no troba la diplomatura facil. Un $65,4 \%$ dels estudiants prefereixen realitzar la carrera que desitgen malgrat les possibilitats d'ocupació que aquesta pugui tenir. Aproximadament el $90 \%$ dels estudiants dels dos centres han escollit estudiar la carrera en què es troben en primera opció. En aquest cas podem afirmar que els estudiants d'Empresarials han satisfet les seves expectatives respecte al tipus d'estudis escollits. Tant a Girona com a Sabadell existeix, a nivell de valoracions personals, una relació entre la valoració de les possibilitats de prestigi (VPP) i ingressos (VIP). Es tendeix a associar el possible prestigi que "hom creu" que tenen els estudis d'Empresarials a les possibilitats d'obtenir en un futur uns ingressos "raonables» en el mercat de treball.

Les valoracions personals també es relacionen amb el que es percep o amb el que es creu que valora la societat. Així, la valoració personal de les possibilitats de prestigi dels estudis (VPP), augmenten en la mesura que la societat valora les possibilitats d'ocupació (VOG). La valoració de les possibilitats d'arribar a tenir prestigi (o consideració social) que els enquestats atribueixen a la seva carrera (VPG) es relacionaven --com hem vist- positivament amb les d'obtenció d'ingressos a nivell personal (VIP). També ho fan amb aquestes últimes a nivell social (VIG). En últim terme podem intuir que el prestigi dels estudis que s'estan realitzant està en funció dels ingressos futurs que s'esperen obtenir a través del desenvolupament de la vida laboral. Aquesta percepció de l'estudiant coincideix amb la que ell mateix pensa que té la societat.

$\mathrm{Al}$ nivell de significació del 95\%, la diferència més destacable entre Girona i Sabadell resideix en el fet que tant les valoracions personals sobre les possibilitats d'obtenció d'ingressos (VPP), com les d'obtenció d'ingressos que realitza la societat són més altes en aquells estudiants que diuen que tenen pares de procedència geogràfica de fora de Catalunya (GFP2). En el moment de 
l'elecció dels seus estudis un percentatge important d'estudiants hagués preferit matricular-se en la llicenciatura en lloc de fer-ho en la diplomatura. La decisió entre diplomatura i llicenciatura es distribueix respectivament a Girona entre el 58,3\% i el 41,7\%. A Sabadell entre el 74,36\% i el 25,64\%. (La possibilitat d'accedir directament a estudis de llicenciatura en el cas de Sabadell, a causa de la seva situació respecte de Barcelona, podria explicar la diferència en els percentatges.) A Sabadell hi ha una relació significativa (nivell de confiança del 95\%) entre nivell d'estudis que es vol realitzar i estudis previs. A mesura que els estudis del pare són més elevats, s'hauria preferit en més gran mesura haver començat a estudiar la llicenciatura. La mitjana d'hores setmanals dedicades a l'estudi és de 12 a Girona i d'11,6 a Sabadell. La diferència és significativa (nivell de confiança del 95\%).

\section{$V$. Costos dels estudis}

Respecte als costos privats mitjans que assumeixen els estudiants o les seves famílies, cal destacar, tal com s'il.lustra en el gràfic 1 . El pagament de la matrícula $\mathrm{i}$ les taxes acadèmiques (el tipus de matrícula dominant és l'ordinària, amb un cost mitjà de 65.128 pessetes a Girona i 73.814 a Sabadell).

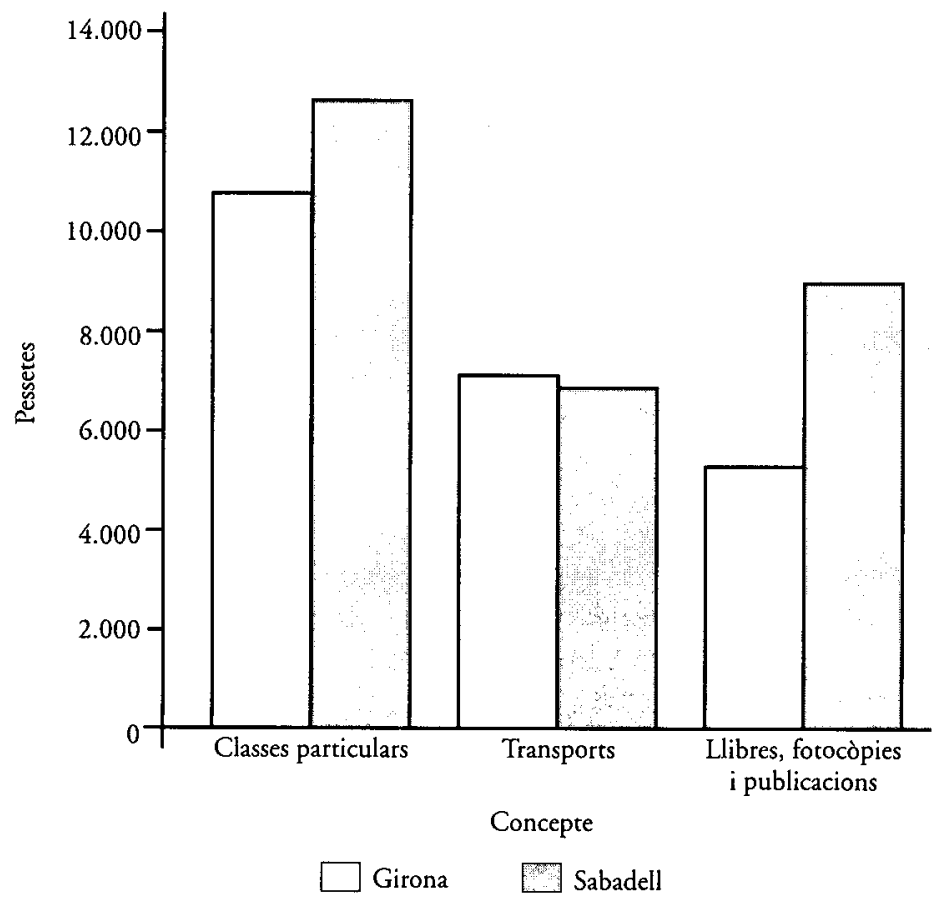

Gràfic 1. 
La diferència és significativa (nivell de confiança del 95\%). (Aquesta diferència podria explicar-se pel nombre més gran d'assignatures pendents en el cas de Sabadell.)

- Classes particulars (10.939 ptes./mes a Girona i 12.657 ptes./mes a Sabadell). La diferència és significativa (nivell de confiança del 95\%).

— Transport: 7.199 ptes./mes a Girona i 6.985 ptes./mes a Sabadell,

— Llibres, fotocòpies i publicacions: 5.373 ptes./mes a Girona i 9.713 ptes./mes a Sabadell. La diferència és significativa (nivell de confiança del $95 \%$ ).

\section{Situació laboral dels alumnes}

De mitjana a Girona els estudiants que treballen ho fan amb una dedicació d'unes 10,3 hores setmanals, mentre que a Sabadell és de 17,3 hores setmanals. La diferència és significativa (nivell de confiança del 95\%). Cal assenyalar, però, que aproximadament un $65 \%$ dels estudiants manifesten que no treballen. Dels estudiants que treballen, en la seva majoria ho fan com a personal administratiu.

\section{Perspectives de futur}

Les tres quartes parts dels estudiants gironins tenen intenció de continuar els seus estudis un cop obtinguin la diplomatura. A Sabadell, aquest percentatge és del $65,6 \%$. Altrament pensen, un 31,9\% a Girona i un $48,2 \%$ a Sabadell, que el que estan estudiant prepara realment per a la vida laboral posterior.

\subsection{Anàlisi multivariada}

S'efectuaran dos tipus d'anàlisis:

- una anàlisi de correspondències múltiples que permet visualitzar i identificar modalitats i variables categòriques en funció de les variables definitòries dels eixos factorials, $\mathrm{i}$

- una anàlisi de tipologies que permet l'agrupació dels individus en diferents classes o categories, d'acord amb el que caracteritza els individus de cada classe des d'un punt de vista estadístic.

Per realitzar l'anàlisi de correspondències múltiples escollim com a variables actives que han de definir eixos factorials les corresponents a:

- Variables de perfil de l'enquestat: edat, sexe, estudis previs, llengua dels pares, procedència geogràfica de l'estudiant, categoria socioprofessional.

- Variables d'entorn familiar i social: procedència geogràfica, estudis i categoria socioprofessional del pare i de la mare.

- Altres variables: torn de classes al qual s'assisteix, universitat on s'estudia. 
Sobre aquests eixos factorials es projecten les variables il.lustratives següents:

— Any d'inici dels estudis.

- Valoracions socials dels estudis realitzats quant a possibilitats d'ocupació, prestigi i ingressos.

- Elecció de diplomatura o llicenciatura.

- Aspiracions de graduació acadèmica.

- Preparació per a la vida laboral.

- Tipus de matrícula.

- Actitud davant el risc.

Com a variables contínues il-lustratives escollim:

- Nombre d'assignatures no aprovades.

- Hores de treball.

- Edat.

Un cop realitzada l'anàlisi de correspondències múltiples observem que els dos primers factors expliquen el $20,5 \%$ de la variabilitat de les dades. La projecció de les diferents modalitats estudiades sobre els eixos factorials s'il.lustren en la figura 1. L'eix 1 es pot definir com la "procedència sociogeogràfica". Les variables que es troben en els seus extrems són les de procedència castellana o catalana dels pares dels estudiants, el seu nivell d'estudis i la seva categoria socioprofessional.

En la part esquerra de l'eix es troben els pares de procedència geogràfica catalana, amb estudis secundaris o superiors. La categoria socioprofessional

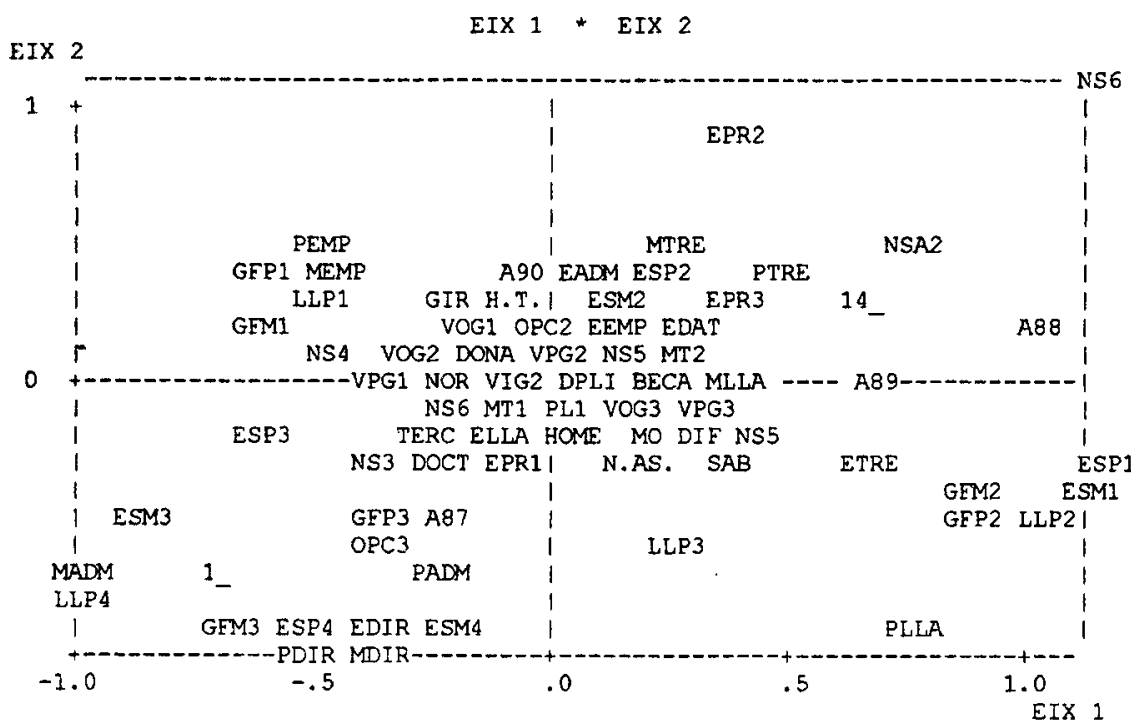

Figura 1. 
del pare és la d'empresari o directiu, i la de la mare, administrativa. En la part dreta trobem els pares de procedència geogràfica no catalana, sense estudis o amb estudis primaris, la seva llengua materna és la castellana, i la categoria socioprofessional és la de treballadors no especialitzats.

Pel que fa a l'eix 2, la seva definició és més imprecisa. L'única variable que cal ressaltar-ne és la dels estudis previs. En l'extrem superior es troben els alumnes procedents de formació professional.

La projecció de la variable que ens indica l'any d'inici dels estudis apareix significativa únicament en les modalitats que indiquen un retard d'un o dos anys respecte a la seva progressió anual, la qual queda associada a la part dreta del primer eix factorial.

La projecció de les variables contínues sobre els eixos factorials no proporciona informació estadística significativa. La correlació amb els eixos factorials és inexistent.

\subsection{Anàlisi de tipologies}

En aquest apartat realitzem una classificació ascendent jeràrquica dels individus caracteritzats per les seves coordenades factorials calculades en l'anterior anàlisi descriptiva factorial utilitzant el criteri d'agregació de Ward. Després d'haver-se realitzat diverses proves, s'ha comprovat que el nombre de classes o tipus que classifiquen millor els alumnes de les institucions estudiades és de tres. La figura 2 ens mostra la projecció dels individus sobre els eixos factorials anteriors.

\section{Primera tipologia}

Les modalitats significatives d'aquesta tipologia ens indiquen que agrupa principalment estudiants que han realitzat l'opció BUP-COU. Els seus pares tenen estudis superiors i són directius o administratius. Les mares són o bé administratives o directives. La seva procedència geogràfica és catalana i la llengua de comunicació amb els pares és també la llengua catalana.

Quant al rendiment acadèmic d'aquesta tipologia, cal destacar que apareix significativa la modalitat que indica un retard en la progressió anual dels estudis de quatre anys. Un 47,6\% dels alumnes amb rendiment acadèmic baix estan comptabilitzats en aquest tipus. Aquest percentatge ens permet veure que l'estatus social no determina per sỉ sol la possibilitat de rendiment acadèmic. El nombre d'individus d'aquesta tipologia és de 60 (un 14,8\% del total).

\section{Segona tipologia}

Caracteritzem en aquesta segona tipologia estudiants amb pares i mares d'origen geogràfic català, de professió empresaris amb estudis primaris o secundaris i que viuen majoritàriament a Girona (un $67,3 \%$ dels alumnes d'aquest grup són de Girona). Creuen que la societat valora molt poc el prestigi social i la possibilitat d'ocupació que proporcionen els seus estudis. (A pesar que aquesta valoració negativa solament representa un $10 \%$ del total dels alumnes enquestats, aquesta tipologia recull el $71,7 \%$ del total.) El seu rendiment acadè- 


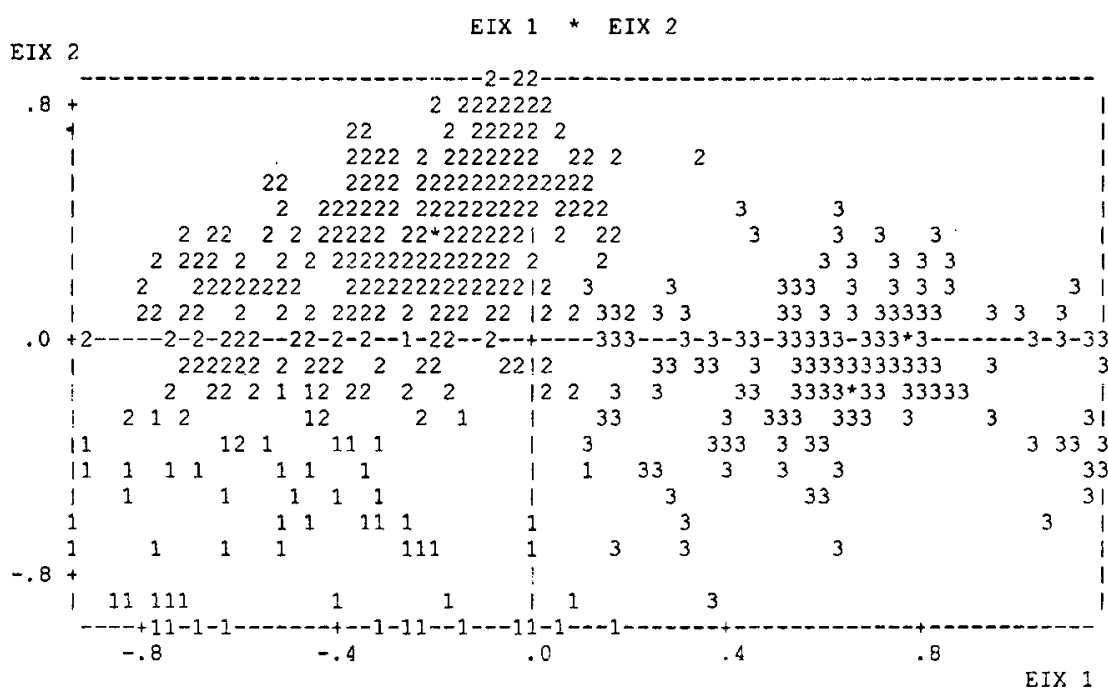

Figura 2.

mic no apareix associat significativament amb variables de retard i no perceben els seus estudis com a difícils. El nombre d'individus d'aquesta tipologia és de 210 (un $58,8 \%$ del total).

\section{Tercera tipologia}

Les modalitats significatives d'aquesta categoria indiquen que es tracta d'estudiants amb pares i mares d'origen geogràfic de fora de Catalunya i de llengua castellana. El seu nivell d'estudis és baix i la seva categoria socioprofessional és la de treballadors no qualificats. Un $69,6 \%$ de les mares dels alumnes que pertanyen a aquest tipus es dediquen a la llar. El 67,4\% dels alumnes d'aquesta tipologia són de Sabadell.

Quant al seu rendiment acadèmic, podem indicar que no és òptim en la mesura que poden portar un curs o dos de retard. Troben que els estudis presenten certa dificultat. En el seu entom social es valoren positivament les possibilitats d'ocupació, ingressos i prestigi dels seus estudis. El nombre d'individus d'aquesta tipologia és de 135 (un 33\% del total).

\section{Conclusions}

En aquest estudi hem pretès comprovar com i en quina mesura les variables que segons la tradició teòrica existent exerceixen la seva influència sobre el rendiment acadèmic, són condicionants d'aquest també en els alumnes de les diplomatures d'Empresarials de Girona i Sabadell. Amb aquesta finalitat, hem estudiat en primer lloc la composició social de l'alumnat (aquí anomenada 
"procedència sociogeogràfica») $\mathrm{i}$ hem comprovat que existeixen diferències significatives entre els alumnes de Girona i Sabadell. Els resultats no són tan concloents en el cas del rendiment acadèmic.

L'anàlisi de les tipologies mostra tres categories socioeconòmiques diferents dels estudiants en base al nivell d'estudis dels pares i a la seva categoria professional:

Tipologia 1: Categoria socioeconòmica «elevada»

Tipologia 2: Categoria socioeconòmica «mitjana»

Tipologia 3: Categoria socioeconònica "baixa»

El rendiment acadèmic baix no pot associar-se a una classe socioeconòmica determinada. Observem un percentatge elevat de retard acadèmic, tant en la tipologia $1 \mathrm{com}$ en la 3. L'escassa variabilitat captada pels dos factors analitzats $(20,5 \%)$ es tradueix en el fet que les característiques determinants de les tres tipologies no estan gaire diferenciades.

Hi ha procedències geogràfiques diferents entre els pares dels estudiants de Girona i Sabadell. Aquestes procedències no condicionen per si mateixes el rendiment acadèmic. El resultat esmentat sembla constatar el fet ja conegut que quan els estudiants arriben a la universitat, ja han estat filtrats en els nivells inferiors del sistema educatiu. A causa de l'escassa associació trobada en aquest estudi entre el rendiment acadèmic dels estudiants i els condicionants socioeconòmics, es podria suposar que el rendiment acadèmic té una relació més gran amb el que al principi d'aquest text hem anomenat "medi universitari".

En aquest treball hem estudiat els alumnes de les diplomatures d'Estudis Empresarials de Girona i Sabadell. Els resultats obtinguts ens obren interrogants respecte a la situació d'altres carreres universitàries. Caldrà ampliar la tasca realitzada en altres investigacions posteriors, amb una mostra més àmplia i diversa d'estudiants. Amb més informació es podrà realitzar una discriminació millor de les variables i una caracterització més bona de les tipologies. Això ens ajudarà a conèixer més bé els possibles filtres o mecanismes de selecció social que operen en el nostre sistema universitari, formalment igualitari, quant a les seves condicions d'accés i permanència.

Annex

\begin{tabular}{lll}
\hline Variable & Valors de la variable & Definició de la variable i/o ítem \\
\hline ANY & A87-A92 & Any d'inici dels estudis \\
ASS & - & $\begin{array}{l}\text { Nombre d'assignatures no aprovades d'altres } \\
\text { cursos (N.AS.) }\end{array}$ \\
HTR & - & $\begin{array}{l}\text { Nombre d'hores de treball a la setmana (de 0 a } \\
\ldots \text { ) (H.T.) }\end{array}$ \\
VOP & VOPi & $\begin{array}{l}\text { Valoració personal dels estudis d'Empresarials } \\
\text { respecte a possibilitats d'ocupació } \\
\end{array}$ \\
& $\mathrm{i}=1, \ldots, 5$ & (VOP1: poques; VOP5: moltes)
\end{tabular}




\begin{tabular}{|c|c|c|}
\hline Variable & Valors de la variable & Definició de la variable i/o ítem \\
\hline VPP & $\begin{array}{l}\text { VPPi } \\
i=1, \ldots, 5\end{array}$ & $\begin{array}{l}\text { Valoracio personal dels estudis d'Empresarials } \\
\text { respecte a possibilitats de prestigi } \\
\text { (VPP1: poques; VPP5: moltes) }\end{array}$ \\
\hline VIP & $\begin{array}{l}\text { VIPi } \\
\mathrm{i}=1, \ldots, 5\end{array}$ & $\begin{array}{l}\text { Valoració personal dels estudis d'Empresarials } \\
\text { respecte a possibilitats d'ingressos } \\
\text { (VIP1: poques; VIP5: moltes) }\end{array}$ \\
\hline VOG & $\begin{array}{l}\text { VOGi } \\
i=1, \ldots, 5\end{array}$ & $\begin{array}{l}\text { Valoració social (gent) dels estudis } \\
\text { d'Empresarials respecte a possibilitats d'ocupació } \\
\text { (VOG1: poques; VOG5: moltes) }\end{array}$ \\
\hline VPG & $\begin{array}{l}\text { VPGi } \\
\mathrm{i}=1, \ldots, 5\end{array}$ & $\begin{array}{l}\text { Valoració social (gent) dels estudis } \\
\text { d'Empresarials respecte a possibilitats de prestigi } \\
\text { (VPG1: poques; VPG5: moltes) }\end{array}$ \\
\hline VIG & $\begin{array}{l}\mathrm{VIGi} \\
\mathrm{i}=1, \ldots, 5\end{array}$ & $\begin{array}{l}\text { Valoració social (gent) dels estudis } \\
\text { d'Empresarials respecte a possibilitats } \\
\text { d'ingressos (VIG1: poques; VIG5: moltes) }\end{array}$ \\
\hline OPC & OPC 1,23 & Opció de tria de la carrera \\
\hline HES & - & Nombre d'hores d'estudi a la setmana \\
\hline DGA & $\begin{array}{l}\text { 1: CUR } \\
\text { 2: DIP } \\
\text { 3: LLIC } \\
\text { 4: TERC } \\
\text { 5: DOCT }\end{array}$ & $\begin{array}{l}\text { Aspiracions acadèmiques (desig de graduació } \\
\text { acadèmica a nivell de cursos solts, } \\
\text { diplomatura, llicenciatura, doctorat) }\end{array}$ \\
\hline DPL & - & $\begin{array}{l}\text { diplomatura (DPL1), versus llicenciatura } \\
\text { (DPL2) }\end{array}$ \\
\hline MTR & $\begin{array}{l}\text { MTRi: } \\
\text { i: } 1, \ldots, 6\end{array}$ & $\begin{array}{l}\text { Tipus de matrícula } \\
\text { ORD: ordinària; BECA: gratuïta o semigratuï- } \\
\text { ta per beques o altres motius }\end{array}$ \\
\hline INV & - & $\begin{array}{l}\text { Cas de tenir els recursos, invertiries en: } 1 \text { : } \\
\text { accions borsa, 2: bons Tresor }\end{array}$ \\
\hline GFP & $\begin{array}{l}\text { GFPi: } \\
\text { i: } 1,2,3\end{array}$ & $\begin{array}{l}\text { Procedència geogràfica del pare: } \\
\text { GFP1: Comarques de Catalunya; GFP2: } \\
\text { Altres comunitats autònomes; GFP3: Altre país }\end{array}$ \\
\hline GFM & $\begin{array}{l}\text { GFMi: } \\
\mathrm{i}: 1,2,3\end{array}$ & $\begin{array}{l}\text { Procedència geogràfica de la mare } \\
\text { GFM1: Comarques de Catalunya; } \\
\text { GFM2: Altres comunitats autònomes; GFM3: } \\
\text { Altre país }\end{array}$ \\
\hline GEE & $\begin{array}{l}\text { GEEi: } \\
\text { i: } 1,2,3\end{array}$ & $\begin{array}{l}\text { Procedència geogràfica de l'estudiant } \\
\text { GFE1: Comarques de Catalunya } \\
\text { GFE2: Altres comunitats autònomes; } \\
\text { GFE3: Alrre país }\end{array}$ \\
\hline ESP & $\begin{array}{l}\text { ESPi: } \\
\text { i: } 1, \ldots, 4\end{array}$ & $\begin{array}{l}\text { Estudis pare: ESP1: sense estudis, } \\
\text { ESP2: primaris, ESP3: secundaris } \\
\text { ESP4: superiors }\end{array}$ \\
\hline ESM & $\begin{array}{l}\text { ESMi: } \\
\text { i: } 1, \ldots, 4\end{array}$ & $\begin{array}{l}\text { Estudis mare: ESM1: sense estudis, } \\
\text { ESM2: primaris, ESM3: secundaris, } \\
\text { ESM4: superiors }\end{array}$ \\
\hline
\end{tabular}




\begin{tabular}{lll}
\hline Variable & Valors de la variable & Definició de la variable i/o ítem \\
\hline SPP & & $\begin{array}{l}\text { Categoria socioprofessional pare (vegeu el qua- } \\
\text { dre de classificació) }\end{array}$ \\
& & $\begin{array}{l}\text { Categoria socioprofessional mare (ídem) } \\
\text { Categoria socioprofessional estudiant (ídem) }\end{array}$ \\
EPR & EPRi: & $\begin{array}{l}\text { Estudis previs actuals: EPR1: COU } \\
\text { amb o sense PAAU, EPR2: FP-II, EPR3: altres }\end{array}$ \\
LLP & i: $1,2,3$ & Llengua parlada amb els pares \\
EDA & i: $1,2,3$ & LLP1: català, LLP2: castellà, LLP3: altres \\
SX & Sxi: & Edat \\
MT & i: 1,2 & Sexe: home, dona \\
GR-SAB & MT1, & Grup: mati (MT1), tarda (MT2) \\
& & 1: GIR, estudiant de Girona \\
2: SAB, estudiant de Sabadell
\end{tabular}

* Les categories socioprofessionals són les següents:

1: Professionals amb titulació superior, tècnics, gerents i professions liberals i professors d'universitat (Pare directiu: PDIR, Mare directiva: MDIR, Estudiant directiu: EDIR)

2: Professionals de l'ensenyament bàsic i mitjà i personal administratiu (Pare: PADM, Mare: MADM, Estudiant: EADM).

3: Empresaris comerciants i venedors («Empresaris»: Pare: PEMP, Mare: MEMP, Estudiant: EEMP).

4: Treballadors de qualsevol branca d'activitat, excloent els tècnics d'aquests sectors (Pare: PTRE, Mare: MTRE, Estudiant: ETRE).

5: Altres: personal forces armades, mestresses de casa (Pare: PLLA, Mare: MLLA, Estudiant: ELLA).

\section{Bibliografia}

ApodaKa, Peio; Grao, Julio; Martínez, Joaquín; Romo, Idoia (1991). Demanda y rendimiento académico en la educación superior. Estudio logitudinal de la inserción de dos cohortes de bachillerato en la UPVIEHU. Eusko Jaurlaritza-Gobierno Vasco.

BERNSTEIN, Basil $(1961,1965)$. "Social Class ans Linguistic Development». A HaLSEY, A.H. y otros (1961). Class, Codes and Control. Londres: Routledge and Kegan Paul, 1965.

BISQUERRA, Rafael (1989). Introducción conceptual al análisis multivariable. Un enfoque informático con los paquetes SPSS-X, BMDP, LISREL y SPAD. Vol. II.

CALERO, Jorge (1993). Efectos del Gasto Público Educativo. El sistema de becas universitarias. Publicacions Universitat de Barcelona.

Calvo, Félix. Estadistica Aplicada. Ediciones Deusto.

CEA D'ANCONA, Francisca; Mora RuIz, José-Ginés (1992). "Análisis socioeconómico de la elección de estudios superiores". Estadistica española, Volumen 34, núm. 129 , p. 61-92.

COMREY, Andrew L. (1985). Manual de análisis factorial. Ediciones Cátedra.

CORBACHO, Joaquín Âlvarez (1988). «Rendimientos y equidad social del Gasto Público universitario. La Universidad Gallega». Papeles de Economía Española, núm. 37. 
DOMENNECH, José M.; PORTELL, Maria (1991). SPSS/PC+ básico Versión V4.0. Documents del laboratori d'Estadística Aplicada i de Modelització. Universitat Autònoma de Barcelona.

EICHER, Jean Claude (1988). «Treinta años de Economía de la Educación», Separata Revista Ekonomiaz, núm. 12.

ETXEBERRIA, Juan i altres (1990). Programación y análisi sestadisticos básicos con SPSS/PC. Madrid: Paraninfo.

LATIESA, Margarita (1992). La deserción universitaria. Centro de Investigaciones Sociológicas. Siglo XXI.

LEGRAND, Louis (1988). Les politiques de l'éducation. Qué says-je? Presses Universitaires de France.

MANZANO ARRONDO, V. (1989). Domine el SPSS/PC+. Ed. RA-MA

Maurice, M.; Sellier, F.; SilveSTRE, J.J. (1982). Política de Educación y Organización Industrial en Francia y Alemania. Publicación del Ministerio de Economía y Seguridad Social (1987).

Moltó, Tomás; Oroval, Esteve (1993). Planificación de la Enseñanza Superior. Escenarios para el sistema público de la CAPV. Departamento de Educación, Universidades e Investigación. Eusko Jaurlaritza-Gobierno Vasco.

MOLTO, Tomàs; OROVAL, Esteve (1984). Costos y rendimientos en la Enseñanza Superior. ICE-UAB. Col-lecció Informes, I-26.

Mora Ruiz, J.G.; Palafox, J.; Pérez García, F. (1993). La financiación de las universidades valencianas. Ediciones Alfons el Magnànim. Generalitat Valenciana i Diputació Provincial de València.

MORA Ruiz, José Ginés; CEA, Francisca (1992). «Análisis socioeconómico de la elección de estudios superiores». Estadística Española. Volumen 34, núm. 129.

PAGE, André. L'économie de l'education. SUP-COLLECTION. Press Universitaires de France.

QuINTAS, Juan Ramon (1983). Economía y Educación. Editorial Pirámide.

SOLÉ, Joan (1991). El rendimiento académico en las Escuelas Universitarias de Estudios Empresariales: Una aproximación desde la Economía. Trabajo no publicado. 